\title{
Urban Growth and Sustainable Development in Shenzhen City 1980-2006
}

\author{
Jianfa Shen ${ }^{*}$
}

Department of Geography and Resource Management, The Chinese University of Hong Kong, Shatin, NT, Hong Kong

\begin{abstract}
This paper examines the rapid urban growth in the city of Shenzhen with particular focus on urban economic growth, population growth, agriculture and environmental changes. With the rapid expansion of population and the builtup area, there is increasing demand for the provision of urban infrastructure. The volume of environmental pollution is also increasing. The problems of environmental pollution and the negative impact on agriculture have also been examined in the paper. Shenzhen's agriculture has undergone a transition from general agriculture to the rise and eventually decline of suburban agriculture. Shenzhen's case indicates that it is possible to move towards balanced development in social, economic and environmental dimensions even for new large cities like Shenzhen.
\end{abstract}

Keywords: Urban growth, population growth, agriculture, environmental pollution, sustainable development.

\section{INTRODUCTION}

Many studies have been carried out on economic development and urbanization in China [1-5]. Some studies have also raised concerns of environmental consequences and implications for resources utilization of China's recent rapid development [6-9]. As China steadily moves forward to become an industrialized and urbanized society, huge environmental impacts might be produced. Officially, Chinese government has launched Agenda 21 and introduced a series of laws and regulations for environment protection and sustainable development. A perspective of scientific development is emphasized to achieve resource and energy efficiency for sustainable development in recent years. Major problems remain in implementation and enforcement as local governments often give priority to economic development.

This paper will use the city of Shenzhen as a case study to examine urban development and its environmental implications in China. Although Shenzhen currently does not experience significant overurbanization, high unemployment and poverty problems which are common in many developing countries $[10,11]$, it does face increasing pressure of population growth, land use and environmental pollution.

Pearl River Delta is one of the most rapidly developing regions in China. There are two special economic zones in the Pearl River Delta, namely, Shenzhen and Zhuhai which were designated by the Chinese Government in 1980. The special economic zones have been the testbed of China's economic reform and open door policies in the 1980s and 1990s to take advantage of their close ties with Hong Kong and Macao. For example, a series of housing reform policies and programmes have been introduced in Shenzhen special economic zone (SEZ) to promote housing commodification and housing ownership [12]. Shenzhen is also a pioneer in

\footnotetext{
*Address correspondence to this author at the Department of Geography and Resource Management, The Chinese University of Hong Kong, Shatin, NT, Hong Kong; E-mail: jianfa@cuhk.edu.hk
}

urban planning and in adopting market mechanisms for the allocation of land resources [13].

Currently, there are six districts in Shenzhen city. Four belong to the Shenzhen special economic zone (Futian, Luohu, Nanshan and Yantian districts) and other two districts (Baoan and Longgang districts, designated by dividing former Baoan county) are not part of the special economic zone. There is an internal boundary between the special economic zone and non-special economic zone which is also called the second boundary in contrast to the first boundary between Hong Kong and Shenzhen special economic zone. There was tight control in the secondary boundary in the 1980 s and 1990s but this has been relaxed in recent years. The total area of Shenzhen city is $1952.84 \mathrm{~km}^{2}$ which almost doubles the size of Hong Kong and the area of the Shenzhen special economic zone is $395.82 \mathrm{~km}^{2}$ [14]. Shenzhen is ideally positioned nearby Hong Kong to act as the window of China to the outside world. Indeed, Hong Kong is densely populated with a population of about 7 million with limited land resources. In the last three decades, Hong Kong investors have invested heavily in Shenzhen and other cities in Pearl River Delta for industrial and non-industrial development. Hong Kong and Shenzhen have very close economic and trade ties $[15,16]$. Shenzhen provides many opportunities for Hong Kong's capital and information resources, and management skills. There are increasing concerns on intercity competition and the needs for cooperation between Hong Kong and Shenzhen [17].

There has been rapid economic, population and urban growth in Shenzhen. The pace of development is beyond the imagination of many people and the initial projection of planners in the Shenzhen Planning Bureau in 1981. The initial projected population in the Shenzhen SEZ was 0.4 million in 1990 and 1.0 million by the year 2000 which was reached in 1985 and 1989 respectively. The population in the Shenzhen special economic zone was increased to 1.51 million in 1995 and 3.19 million in 2006. For the city of Shenzhen as a whole, its population was increased to 4.49 
million in 1995 and 8.46 million in 2006 [14]. The population figure is based on the official statistics including population who stayed in Shenzhen over half year.

Some studies have focused on the development in Shenzhen [18-20]. Sun considered the issue of future development in Shenzhen in the context of Pearl River Delta and its relation with Hong Kong while $\mathrm{Ng}$ reviewed the urban development and planning of the city [21-22]. On the other hand, Hsu, Ng, Lai and Yang considered the environmental problems in Shenzhen SEZ in the context of its geographical setting and industrialization-lead economic growth [23-25]. The contrast and the relation between Hong Kong and Shenzhen have also been the focus of recent studies [24, 26]. Liu et al. examined the relationship between development level and environment for the period 1989-2003 [27]. They found that environment quality related to $\mathrm{NO}_{\mathrm{x}}$ and total suspended particulates in the air and BODs and total phosphorus in Shenzhen river improves with development. But some pollutants induced by consumption such as $\mathrm{SO}_{2}$ increased with development. Population growth and concentration seems to causing environmental stress in the city.

The rest of the paper is organized into five sections. The following section will discuss the urban economic growth. Section three will examine the population growth and migration in Shenzhen. Section four will analyze the impact of rapid urban growth on agriculture and environment. Some conclusions are reached in the final section.

\section{URBAN ECONOMIC GROWTH}

Shenzhen special economic zone has implemented a series of favourable and flexible policies to attract investment and stimulate economic growth [28-30]. These favourable conditions have attracted much investment from Hong Kong and abroad. China's domestic capital has also quickly moved into Shenzhen to take the advantage of its close economic and trading ties with Hong Kong and the overseas market. There has been dramatic growth both in terms of GDP (Gross Domestic Product) per capita and the total GDP.

The GDP in the city of Shenzhen was greatly expanded from RMB 196 million in 1979 to RMB 581 billion by the year 2006. During the period 1980-1994, the GDP was growing at a rate of more than $30 \%$ a year in most years. There was also high growth of $14-20 \%$ a year in the period 1995-2006. The GDP per capita in the city was also increased rapidly from only RMB 835 in 1980 to RMB 69450 (US\$8712) by the year 2006 .

The GDP per capita growth rate was negative only in two years, 1986 and 1989 when GDP growth was relatively slow. Table 1 compares the GDP per capita in China, Guangdong province, Pearl River Delta and the city of Shenzhen. The most noticeable is the similar levels of GDP per capita in these areas in 1980 when the economic reform began. The development process since 1980 greatly altered this regional balance. By the year 2006, Shenzhen city has become one of the most advanced cities in China.

Shenzhen's economic structure has also undergone significant change in this rapid growing period. There has been steady shift from primary sector to the secondary sector while the tertiary sector has been relatively stable. The share of secondary sector in GDP increased from $26.0 \%$ in 1980 to $53.4 \%$ in 1993 and then stabilized to reach $52.5 \%$ in 2006 . The share of tertiary sector in GDP was stable at $45.1 \%$ in 1980 and $47.4 \%$ in 2006. By the year 2006, the secondary sector was the largest sector which accounted for $57.43 \%$ of all employees in the city of Shenzhen. The SEZ provides more service functions than areas outside the SEZ in the city. In 2006 , the tertiary sector accounted over $62.9 \% \%$ of GDP while the share of secondary sector was below $38 \%$ in $\mathrm{Fu}$ tian, Luohu and Yantian districts. Nanshan district had an economic structure similar to that of Baoan and Longgang districts with the share of secondary industry in GDP around $66-67 \%$ [14].

Rapid economic growth in Shenzhen is made possible by the heavy inflow of capital, labour and associated technology and information. Many studies tended to emphasize the role of foreign investment while the contribution of domestic investment was often ignored. However, Hu, Shen, Wong and $\mathrm{Chu}$ found that the investment from domestic enterprises also formed quite a large portion of the total investment [3132].

Table 1. GDP Per Capita in China, Guangdong, Pearl River Delta and the City of Shenzhen 1980-2006

\begin{tabular}{|c|c|c|c|c|}
\hline Year & China & Guangdong & Pearl River Delta & City of Shenzhen \\
\hline \hline $1980(\mathrm{RMB})$ & 463 & 481 & 500 & 835 \\
\hline $1985(\mathrm{RMB})$ & 858 & 1026 & n.a. & 4809 \\
\hline $1990(\mathrm{RMB})$ & 1644 & 2484 & 3148 & 18242 \\
\hline $1995(\mathrm{RMB})$ & 5046 & 8129 & 18094 & 32800 \\
\hline $2000(\mathrm{RMB})$ & 7858 & 12736 & 41990 & 60801 \\
\hline $2005(\mathrm{RMB})$ & 14040 & 24438 & 49153 & 69450 \\
\hline $2006(\mathrm{RMB})$ & 15973 & 28332 & 6166 & 8712 \\
\hline $2006(\mathrm{US} \$)$ & 2004 & 3554 & & 6 \\
\hline
\end{tabular}

Data sources: [14, 30, 48-54].

Note: US\$1=RMB7.9718 in 2006 [53]. GDP per capita in Pearl River Delta in 1980-1995 was based on hukou population and would be smaller than the figure if large total population was used. 
Recent statistical data provided further evidence. Table $\mathbf{2}$ presents the total investment and foreign direct investment (FDI) in the city of Shenzhen over the period 1981-2006. The original data are in terms of RMB and have been translated into US dollars using annual average official exchange rate. In 1995, the main sources of FDI in the city were Hong Kong (60.3\%), Japan (18.5\%), USA (8.2\%), Taiwan (4.0\%), UK $(0.6 \%)$ and Singapore (0.5\%) [36]. In 2006, the main sources of FDI were Hong Kong (51.2\%), Singapore (3.5\%), USA (2.2\%), Japan (1.4\%), Taiwan (0.9\%), Germany $(0.7 \%)$, Netherlands $(0.7 \%)$ and UK $(0.5 \%)$. The sources become more diversified and other sources contributed over $39.0 \%$ in 2006 [14].

Several points are clear about the investment trends in the city of Shenzhen and the Shenzhen special economic zone. First, there has been massive investment in the city of Shenzhen. The total investment in the city of Shenzhen amounts to US\$125.92 billion and the foreign investment US\$33.74 billion over the period 1981-2006. Second, both the domestic and foreign investment had been increasing steadily in that period with slight fluctuations. Annual total investment increased from US $\$ 0.17$ billion in 1981 to US\$3.30 billion in 1995 and US\$15.98 billion in 2006. Annual foreign direct investment increased from US\$0.09 billion in 1981 to US\$1.31 billion in 1995 and US\$3.27 billion in 2006. Third, both domestic and foreign capitals are important sources of investment in the city of Shenzhen. FDI has been particularly important in the period 1981-1996 accounting for over $50 \%$ of the total investment in a few years. FDI accounted for $26.79 \%$ of the total investment in the period 1981-2006. Fourth, the main destination of FDI in the city is the special economic zone. It seems that such concentration is decreasing in the recent years. About $90 \%$ of FDI was concentrated in the special economic zone over the period 1981-1991. But the proportion of FDI in the special economic zone was gradually declined to only $60 \%$ by 1995 .

Capital is one of the three main production factors in addition to labour and technology. In a city like Shenzhen with sufficient supply of both skilled and unskilled labour from various areas, capital is perhaps one of the main forces in stimulating economic development. On the other hand, suitable technology can be imported and utilized with efficient management and a skilled labour force. The relationship between the GDP (G), FDI (I) and domestic investment (D) in Shenzhen city is analyzed using regression analysis. The data series covers a period of 26 years from 1981 to 2006 and all data take log transformation. Following regression equation is obtained. T-values of the regression coefficients are provided in brackets.

$\operatorname{Ln} \mathrm{G}=1.302+0.565 \mathrm{Ln} \mathrm{I}+0.645 \mathrm{Ln} \mathrm{D}$

(15.224) (8.043) (9.118)

$\mathrm{R}^{2}=0.997 ; \quad$ Adj. $\mathrm{R}^{2}=0.993 ; \quad \mathrm{F}=1686$

The above equation shows a close relationship between the GDP output, FDI and domestic investment.

\section{MIGRATION AND POPULATION GROWTH}

Economic growth and massive investment in Shenzhen have generated a number of job opportunities and have attracted many migrants from various areas in China. Recent estimate indicates that Shenzhen had a population of 8.46 million in year 2006. This figure includes 1.97 million registered population (Hukou population) whose residence registration (Hukou) was in Shenzhen and 6.50 million temporary population (non-Hukou population) whose residence registration was not in Shenzhen but had stayed in Shenzhen for over six months. Here Hukou registration refers to official ways that ordinary Chinese register with government either as agricultural population or as non-agricultural population at a particular place. The transfer and change of such Hukou registration between places and from the status of agricultural population to that of non-agricultural population are still largely under tight control despite important progress in hukou reform [4]. However, people have been allowed to move to other areas and to register temporary with the government at their place of residence and employment since 1984 [1, 2, 4, 33]. Therefore, there are two kinds of migrants in China. Hukou migrants who transfer their Hukou registration along with their move and non-Hukou migrants who

Table 2. Total and Foreign Direct Investment in the City of Shenzhen 1981-2006

\begin{tabular}{|c|c|c|c|c|}
\hline Year & $\begin{array}{c}\text { Total Investment } \\
\text { (RMB Billion) }\end{array}$ & $\begin{array}{c}\text { Total Investment } \\
\text { (US\$ Billion) }\end{array}$ & $\begin{array}{c}\text { FDI in the City } \\
\text { (US\$ Billion) }\end{array}$ & $\begin{array}{c}\text { FDI Share of Total } \\
\text { Investment (\%) }\end{array}$ \\
\hline \hline 1981 & 0.30 & 0.17 & 0.09 & 49.61 \\
\hline 1985 & 3.33 & 1.13 & 0.18 & 5.36 \\
\hline 1986 & 2.49 & 0.72 & 0.39 & 29.92 \\
\hline 1990 & 6.23 & 1.30 & 1.31 & 39.66 \\
\hline 1995 & 27.58 & 3.30 & 2.05 & 52.06 \\
\hline 1996 & 32.75 & 3.94 & 1.66 & 35.03 \\
\hline 1997 & 39.31 & 4.74 & 1.96 & 26.20 \\
\hline 2000 & 61.97 & 7.49 & 2.97 & 20.59 \\
\hline 2005 & 118.11 & 14.42 & 3.27 & 20.46 \\
\hline 2006 & 127.37 & 15.98 & & \\
\hline
\end{tabular}

Source: calculation by the author and also $[14,53]$. 
only register as temporary population at their destination but leave their Hukou registration at their origin. Most of the Hukou migrants are professional, technical and high skilled persons whose number is much smaller than that of nonHukou migrants.

Table 3 presents the growth of hukou population and temporary population in the city of Shenzhen. The total population in Shenzhen increased rapidly from 0.31 million in 1979 to 4.49 million in 1995 and 8.48 million in 2006 . Initially, Hukou population accounts for majority of the population in the city. In 1981, the share of Hukou population in the total population was still as high as $91 \%$. However, this proportion was steadily declined to only $22.08 \%$ in 1995 and $17.81 \%$ in 2000 though the number of Hukou population was increased from 0.31 million in 1979 to 1.25 million by 2000 . This is due to the much rapid increase in the temporary population. The temporary population in the city was increased from about 1500 in 1979 to 3.50 million in 1995 and 5.76 million in 2000 . The temporary population accounted for only $0.48 \%$ of the total population in 1979 but it accounted for $82.19 \%$ of the total population in the city in 2000. In the period 2000-2006, the hukou population increased from 1.25 million to 1.97 million and its share in total population increased from $17.81 \%$ to $23.25 \%$. Overall, Shenzhen is an outstanding city in China that its population mainly consists of temporary population.

It will be of interest to examine the population dynamics in Shenzhen SEZ which was presented in Table 4. The total population in SEZ increased rapidly from only 94,100 in 1980 to over 1.51 million in 1995 and 3.19 million in 2006. Both the Hukou population and temporary population increased over the period. The Hukou population increased from 84,100 in 1980 to 1.23 million by 2006 . The temporary population increased from 10,000 in 1980 to 1.96 million by 2006. In 2006, the temporary population accounted for
$61.52 \%$ of the total population in SEZ. There are several important features in the population dynamics in SEZ which are different from the general population trend of the whole city.

First, two contrasting periods, 1980-1987 and 1988-2006 can be identified (Fig. 1). In the first period, the proportion of temporary population was higher in SEZ than in the whole city. In the second period, the proportion of temporary population was smaller in the SEZ than in the whole city. The areas outside the SEZ actually attracted more temporary population than the SEZ. It appears then that there is a gradual transition toward a more balanced population growth in the SEZ. The share of temporary population was stable around $56-65 \%$ at SEZ in the period 1988-2006. Second, there is no steady increasing trend in the scale of annual population growth especially since 1985 . The annual population growth is also less stable. Third, migration was the major source of population growth in the SEZ.

Population growth in the SEZ and the remaining areas of the city has not been an even process. Initially, rapid population growth took place in the SEZ. There was a concentration period 1980-1985 when more population moved into the SEZ than the remaining areas of the city. The SEZ share of population increased from $28.27 \%$ in 1980 to $53.30 \%$ in 1985 and declined to $29.28 \%$ in 2000 . The SEZ share of population increased again to $37.67 \%$ in 2006 due to residential development and growth of service sector in SEZ (Fig. 2).

With the growth of population in the city of Shenzhen, the built-up area, public utilities and urban infrastructure have also been expanded rapidly. The built-up area of the SEZ increased from less than $3 \mathrm{~km}^{2}$ before the $1980 \mathrm{~s}$ to $48 \mathrm{~km}^{2}$ in $1985,88 \mathrm{~km}^{2}$ in 1995 and $136 \mathrm{~km}^{2}$ in 2000 . The

Table 3. Population Growth in the City of Shenzhen 1979-2006

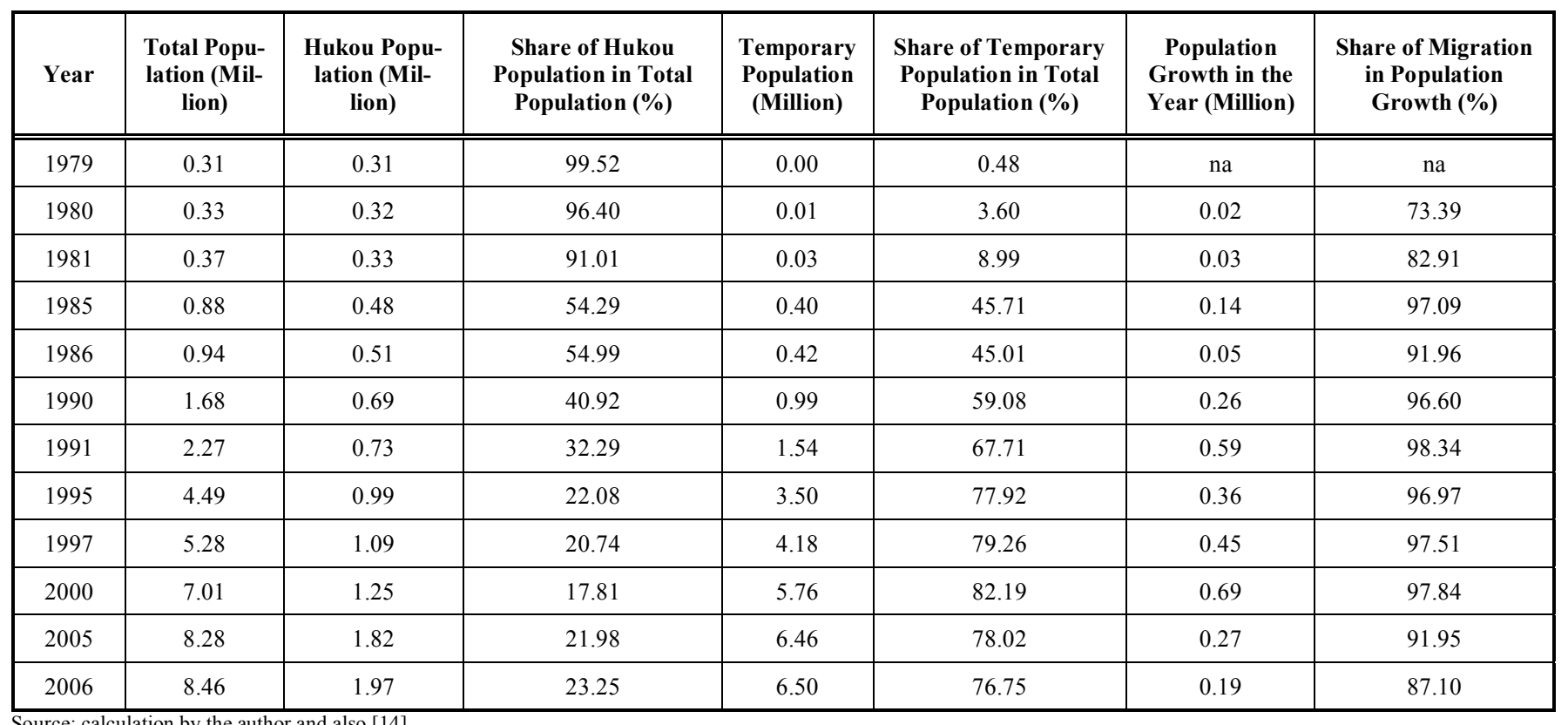


Table 4. Population Growth in the Shenzhen Special Economic Zone 1980-2006

\begin{tabular}{|c|c|c|c|c|c|c|c|}
\hline Year & $\begin{array}{c}\text { Total } \\
\text { Population } \\
\text { (Million) }\end{array}$ & $\begin{array}{l}\text { Hukou } \\
\text { Population } \\
\text { (Million) }\end{array}$ & $\begin{array}{c}\text { Share of Hukou Popu- } \\
\text { lation in Total Popula- } \\
\text { tion }(\%)\end{array}$ & $\begin{array}{c}\text { Temporary } \\
\text { Population } \\
\text { (million) }\end{array}$ & $\begin{array}{l}\text { Share of Temporary } \\
\text { Population in Total } \\
\text { Population (\%) }\end{array}$ & $\begin{array}{l}\text { Population } \\
\text { Growth in the } \\
\text { Year (Million) }\end{array}$ & $\begin{array}{c}\text { Share of Migration } \\
\text { in Population } \\
\text { Growth }(\%)\end{array}$ \\
\hline 1980 & 0.09 & 0.08 & 89.37 & 0.01 & 10.63 & n.a. & n.a. \\
\hline 1985 & 0.47 & 0.23 & 49.36 & 0.24 & 50.64 & 0.13 & 98.27 \\
\hline 1986 & 0.49 & 0.26 & 52.67 & 0.23 & 47.33 & 0.02 & 87.16 \\
\hline 1990 & 1.01 & 0.40 & 39.15 & 0.61 & 60.85 & -0.02 & 136.18 \\
\hline 1991 & 1.20 & 0.43 & 36.07 & 0.77 & 63.93 & 0.19 & 96.43 \\
\hline 1995 & 1.51 & 0.60 & 39.66 & 0.91 & 60.34 & 0.04 & 80.45 \\
\hline 1996 & 1.60 & 0.63 & 39.48 & 0.97 & 60.52 & 0.09 & 92.95 \\
\hline 1997 & 1.75 & 0.68 & 38.90 & 1.07 & 61.10 & 0.15 & 95.51 \\
\hline 2000 & 2.05 & 0.78 & 38.15 & 1.27 & 61.85 & 0.15 & 93.41 \\
\hline 2006 & 3.19 & 1.23 & 38.48 & 1.96 & 61.52 & 0.05 & n.a. \\
\hline
\end{tabular}

Sources: Calculation by the author and also [14, 37].

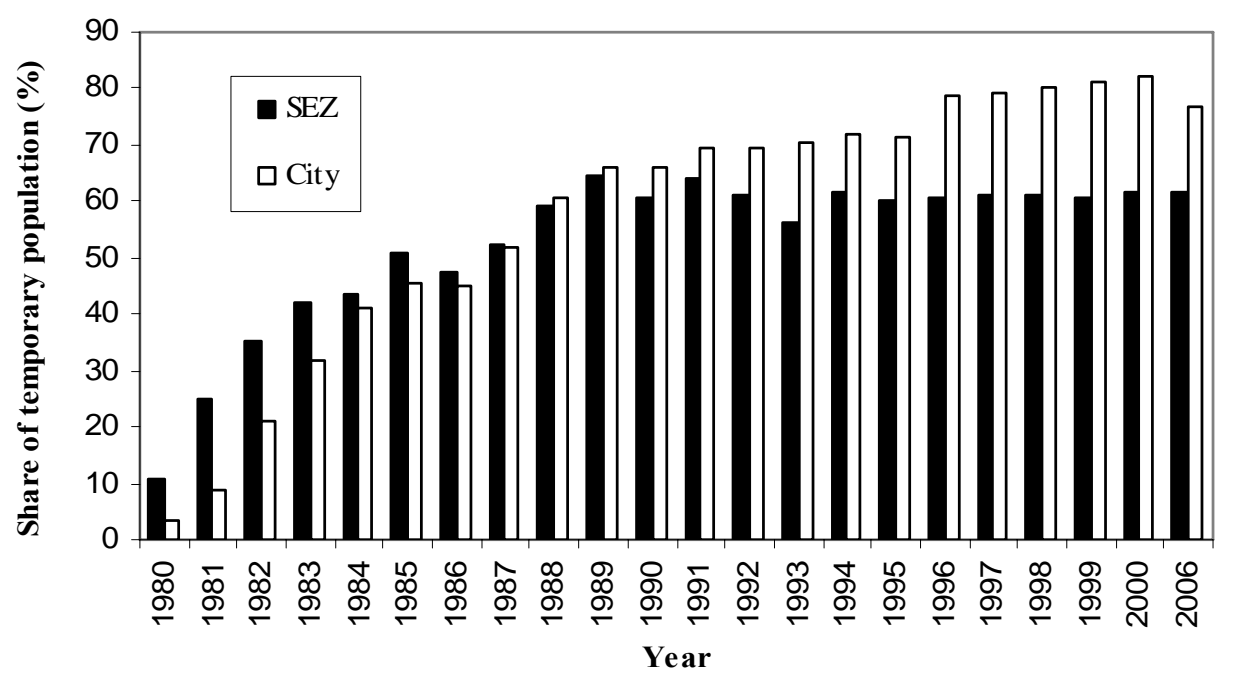

Fig. (1). Share of temporary population in the SEZ and the city of Shenzhen.

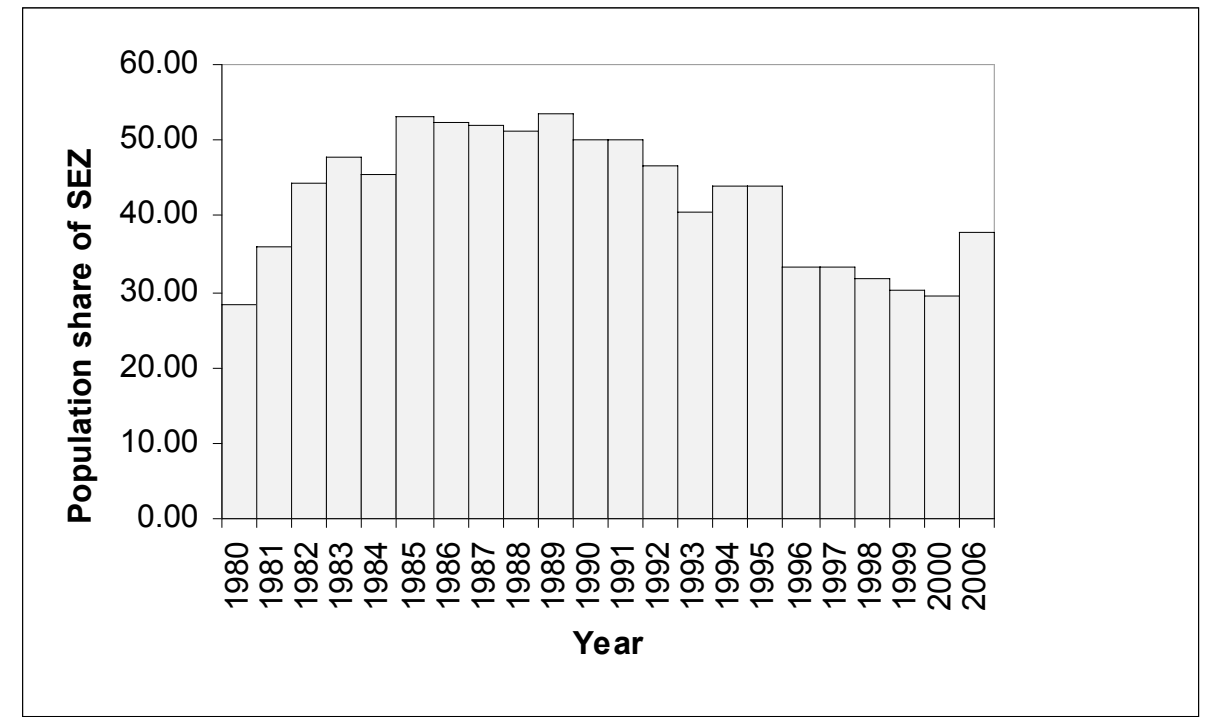

Fig. (2). Population share of SEZ in Shenzhen city. 
total built-up area of the city increased from $495 \mathrm{~km}^{2}$ in 2002 to $720 \mathrm{~km}^{2}$ in $2006[14,34]$. The construction of urban infrastructure and housing in Shenzhen was set at a higher standard than many other cities in China, especially for those with middle income or above $[12,35]$. Taken the housing as an example, the living floor space per capita in SEZ increased from $7.86 \mathrm{~m}^{2}$ in 1985 to $14.14 \mathrm{~m}^{2}$ by 2000 [36-37]. The living floor space per capita in the city increased from $14.73 \mathrm{~m}^{2}$ in 1985 to $22.75 \mathrm{~m}^{2}$ by 2004 . It then declined slightly to $18.31 \mathrm{~m}^{2}$ and $19.72 \mathrm{~m}^{2}$ in 2005 and 2006 when non-hukou population was also taken into account [14]. It is clear that the SEZ not only managed to provide housing in pace with the rapid population growth but also was able to raise the living floor space per capita in the 1980s and 1990s. According to 2000 census, the living floor space per capita in urban areas (city area and town area) was $23.75 \mathrm{~m}^{2}$, greater than other main cities in China such as Guangzhou $\left(22.49 \mathrm{~m}^{2}\right)$, Beijing $\left(22.04 \mathrm{~m}^{2}\right)$, Tianjin $\left(20.03 \mathrm{~m}^{2}\right)$ and Shanghai $\left(22.60 \mathrm{~m}^{2}\right)[38-39]$.

However, there is no detailed housing information on the population which is not covered by the available housing data. The 2000 census did not collect housing data for those who stay in collective households. There were 3.88 million people in a total of 0.78 million collective households in Shenzhen in 2000 [40]. Most of them are temporary population or migrant workers lived in dormitories provided by employers. Their housing condition is likely to be more crowded than the population living at their own home. This may result in many social problems in long term although some migrant workers intend to go to their home town after a few years [41-42]. Overall, rapid population growth and the inflow of migrant labours have also induced great social problems such as housing provision, education and increasing crime rates. This will affect sustainable social development of the city. The city government should pay more attention to social and environmental sustainability in addition to urban economic growth [24].

\section{IMPACT ON AGRICULTURE AND ENVIRON- MENTAL POLLUTION}

Shenzhen provides a good case for examine the impact of recent rapid urban growth and industrialization on agriculture and environment in China [8]. The issue of shrinking agricultural land and food supply has raised the question of who will feed China [43-44]. Shenzhen's agriculture has also experienced significant change due to its rapid urbanization process (Tables 5 and 6). Arable land in the city has been greatly reduced from 532 thousand Mui (15 Mui equal to one hectare) in 1979 to only 29 thousand Mui by 2006 . This also resulted in a dramatic decline of grain production which uses extensive arable land. The grain output of the city reduced from 132,584 ton in 1979 to only 2028 ton in 2004 and 59 Ton by 2006. It is clear that Shenzhen has been transformed to a situation similar to Hong Kong which import majority of its food supply from outside the city. The change in other cities is smaller. For example, the arable land in Guangzhou declined from 186 thousand Mui in 1978 to 130 thousand Mui in 2005. Total grain output declined from the highest of 1.26 million ton in 1984 to only 0.52 million ton in 2005[45].

There are two stages in agricultural change. In the first stage 1979-2002, the agriculture was transformed from general agriculture into a type of suburban agriculture with major expansion in vegetable and meat production. Such suburban agriculture uses relatively less land but with a high output value per unit of land. During the period 1979-1991, the vegetable output in Shenzhen increased by 28 times from 8639 ton a year to 238,716 ton a year. The meat output increased by 11 times from 6726 ton to 79,022 ton in the same period. During the period 1991-2002, the meat production seems to be stabilized while the vegetable production was less stable.

In the second stage 2002-2006, the suburban agriculture began to decline in Shenzhen due to further urban expansion. The production of both meat and vegetables declined in the

Table 5. Agricultural Change in the City of Shenzhen 1979-2006

\begin{tabular}{|c|c|c|c|c|c|}
\hline Year & Arable Land (1000 Mui) & Grain Output (Ton) & Vegetable Output (Ton) & Meat Output (Ton) & Agricultural Output (RMB Million) \\
\hline \hline 1979 & 532 & 132584 & 8639 & 6726 & 131 \\
\hline 1980 & 490 & 126461 & 14593 & 4296 & 2778 \\
\hline 1981 & 460 & 116489 & 22772 & 22932 & 242 \\
\hline 1985 & 339 & 94465 & 162898 & 62513 & 458 \\
\hline 1990 & 280 & 81018 & 227346 & 79022 & 1192 \\
\hline 1991 & 227 & 59138 & 238716 & 74081 & 1431 \\
\hline 1992 & 155 & 32906 & 201517 & 70277 & 1853 \\
\hline 1995 & 66 & 4887 & 147171 & 65911 & 2327 \\
\hline 1997 & 64 & 4990 & 169683 & 79893 & 2709 \\
\hline 2000 & 60 & 3700 & 210479 & 46846 & 3114 \\
\hline 2005 & 37 & 599 & 141652 & 42478 & 2174 \\
\hline 2006 & 29 & 59 & 111509 & & 1800 \\
\hline Source: [14]. & & & & & \\
\hline
\end{tabular}


Table 6. Agricultural change in Shenzhen special economic zone 1980-1995

\begin{tabular}{|c|c|c|c|c|c|}
\hline Year & Arable Land (1000 Mui) & Grain Output (Ton) & Vegetable Output (Ton) & Meat Output (Ton) & Agricultural Output ( RMBMillion) \\
\hline \hline 1980 & 60.70 & 13950 & 2954 & n.a. & 52 \\
\hline 1981 & 52.90 & 11977 & 8884 & n.a. & 45 \\
\hline 1985 & 18.50 & 2906 & 26735 & n.a. & 50 \\
\hline 1990 & 17.80 & 332 & 35381 & 4408 & 127 \\
\hline 1992 & 11.80 & 319 & 26709 & 4252 & 162 \\
\hline 1995 & 4.40 & n.a. & 14502 & 4853 \\
\hline
\end{tabular}

Source: [34].

period. It is noted that agricultural output increased from RMB 131 million in 1979 to the peak of RMB 3408 million in 2002 and it then declined to RMB 1800 million in 2006, the 1992 level. There are similar trends in Shenzhen special economic zone but are much more outstanding as it the focus of urban development. Table 6 shows the changes in the period 1979-1995 for SEZ.

With the expansion of urban and industrial activities, environmental pollution is also increasing in Shenzhen. Table 7 presents the data on environmental pollution for Shenzhen special economic zone for the period 1990-2005. The environmental problems range from air pollution, water pollution, solid waste and noise pollution to soil pollution and land conservation. The discussion here is focused on waste water, water pollution and air pollution. The amount of waste water in the SEZ increased from 136.85 million ton in 1990 to 270.42 million ton by 1995. Part of such increase was due to the increase of population in the SEZ. However, the amount of waste water per capita was also increased from 135.52 ton in 1990 to 172.45 ton in 2000 . This means that about $27.25 \%$ of the increase in waste water in the SEZ was due to the increase in the level of waste water discharge per capita and $72.75 \%$ was due to the increase in the population. The amount of industrial waste water in the SEZ was also increased from 15.52 million ton in 1990 to 26.49 million ton in 2000 . However, there is no increase in the amount of industrial waste water per capita. The proportion of the industrial waste water which was in accord with the standard was raised from $78.03 \%$ in 1990 to $98.23 \%$ by 2000 .

The data for SEZ and whole city are available for comparison in 2000. The waste water per capita was 105.03 ton in the Shenzhen city, lower than that of SEZ. But industrial waste water per capita was 31.10 ton for the city as a whole, much higher than that of SEZ. The difference reflects the concentration of industrial water use in areas out of SEZ. It is noted that the waster water per capita increased to 134.82 ton in 2005 for the whole city although the proportion of the industrial waste water which was in accord with the standard was raised to $96.8 \%$ in 2005 .

Air pollution data are available for the whole city of Shenzhen [14]. The average concentration of the inhalable particles increased from $0.059 \mathrm{mg}$ per $\mathrm{m}^{3}$ in 2000 to the peak of $0.076 \mathrm{mg}$ per $\mathrm{m}^{3}$ in 2004 and then declined slightly to $0.064 \mathrm{mg}$ per $\mathrm{m}^{3}$ in 2006. The average concentration of $\mathrm{SO}_{2}$ increased from $0.012 \mathrm{mg}$ per $\mathrm{m}^{3}$ in 1996 to $0.027 \mathrm{mg}$ per $\mathrm{m}^{3}$ in 2000 and $0.030 \mathrm{mg}$ per $\mathrm{m}^{3}$ in 2006 .

The pressure of urban growth on agriculture and environment is clear in Shenzhen. In recent years, Shenzhen government has made efforts to investment in more facilities for waste processing, tightening environmental standards for waste disposal and adjusting industrial structure towards

Table 7. Water pollution in Shenzhen Special Economic Zone 1990-2005

\begin{tabular}{|c|c|c|c|c|c|}
\hline Year & $\begin{array}{l}\text { Waste Water } \\
\text { (Million Ton) }\end{array}$ & $\begin{array}{l}\text { Waste Water Per } \\
\text { Capita (Ton) }\end{array}$ & $\begin{array}{c}\text { Industrial Waste } \\
\text { Water (Million Ton) }\end{array}$ & $\begin{array}{l}\text { Industrial Waste Water } \\
\text { Per Capita (Ton) }\end{array}$ & $\begin{array}{l}\text { Within Industrial } \\
\text { Standard (\%) }\end{array}$ \\
\hline 1990 & 136.85 & 135.52 & 15.52 & 15.37 & 78.03 \\
\hline 1991 & 143.23 & 119.56 & 15.45 & 12.90 & 76.70 \\
\hline 1992 & 174.34 & 142.89 & 15.46 & 12.67 & 84.99 \\
\hline 1993 & 219.12 & 184.23 & 15.75 & 13.24 & 79.75 \\
\hline 1994 & 260.83 & 176.80 & 18.75 & 12.71 & 87.09 \\
\hline 1995 & 270.42 & 178.87 & 21.85 & 14.45 & 88.65 \\
\hline 2000 & 354.05 & 172.45 & 26.49 & 12.90 & 98.23 \\
\hline $2000 *$ & 736.54 & 105.03 & 218.07 & 31.10 & na \\
\hline $2005^{*}$ & 1116.00 & 134.82 & na & na & 96.8 \\
\hline
\end{tabular}

Sources: $[34,36,37]$.

Note: * Refer to the whole city of Shenzhen. 
Table 8. Waste Treatment in Shenzhen and Guangzhou in 2004

\begin{tabular}{|c|c|c|c|c|}
\hline City & $\begin{array}{c}\text { Share of Industrial Waste Water } \\
\text { Discharged Reaching Standard }\end{array}$ & $\begin{array}{c}\text { Share of Residential Waste } \\
\text { Water Processed }\end{array}$ & $\begin{array}{c}\text { Share of Residential } \\
\text { Waste Processed }\end{array}$ & $\begin{array}{c}\text { Rate of re-Using the } \\
\text { Industrial Solid Waste }\end{array}$ \\
\hline \hline Shenzhen & 96 & 63 & 100 & 87 \\
\hline Guangzhou & 92 & 58 & 92 & 93 \\
\hline
\end{tabular}

Source: [47]

high-value added high-tech and capital intensive industries with less environmental pollution. The $11^{\text {th }}$ five-year plan of Shenzhen for the period 2006-2010 aims to promote a new development model emphasizing the recycle of resources [46]. Strict environmental objectives are set to reduce $\mathrm{SO}_{2}$ and COD emission by $10 \%$. $60 \%$ of water quality and $99 \%$ of water resources for drinking will reach standard, $75 \%$ of waste water will be processed centrally, 92\% of industrial solid waste and $45 \%$ of residential waste will be re-used, and $95 \%$ of residential waste will be processed for harmless disposal. These measures will contribute to sustainable urban development in the city.

In comparison, the environmental waste is handled better in Shenzhen than in Guangzhou, the largest and capital city of Guangdong province with a long history. The share of industrial waste water discharged reaching standard, and share of residential waste water processed and the share of residential waste processed in Guangzhou were lower than Shenzhen in 2004 (Table 8). Only Guangzhou had a higher rate of re-using the industrial solid waste (93\%) than Shenzhen (87\%) [47]. Such differences mean that new developed areas can do better than old cities to tackle environmental pollution. Nevertheless, the environmental stress and pollution are still serious and more effort is needed to tackle these problems.

\section{CONCLUSION}

This paper has examined the rapid urban growth in the city of Shenzhen with particular focus on urban economic growth, population growth, agriculture and environmental changes. It is found that net in-migration accounts for the majority of the urban population growth and that both domestic and foreign investments have significant contributions to the rapid economic expansion in the city.

Rapid population growth and the inflow of migrant labours have also induced great social problems such as housing provision and increasing crime rates. The city government should pay more attention to social and environmental sustainability in addition to urban economic growth.

With the rapid expansion of population and the built-up area, there is increasing demand for the provision of urban infrastructure. There is also increasing stress on natural environment and coastal areas which is not discussed in detail in this paper. The volume of environmental pollution is also increasing. Shenzhen as a rapidly expanding city provides a good case to address these issues. The problems of environmental pollution and the negative impact on agriculture have also been examined in the paper. Shenzhen's agriculture has undergone a transition from general agriculture to the rise and eventually decline of suburban agriculture.

Generally, Shenzhen's performance is better than many other major cities in China in terms of environmental protection. Shenzhen's case indicates that it is possible to move towards balanced development in social, economic and environmental dimensions even for new large cities like Shenzhen. Other old and large cities may face even more environmental problems due to inertia in economic structure and historical legacy of poor urban infrastructure. With further industrialization and rising living standards and consumption level, Chinese cities need to invest more in urban infrastructure and environmental protection to achieve sustainable development.

\section{ACKNOWLEDGEMENT}

The work described in this paper was fully supported by a grant from the Research Grants Council of the Hong Kong Special Administrative Region (Project no. CUHK450107/ Geography).

\section{REFERENCES}

[1] Wu CT, Xu X. Economic reforms and rural to urban migration. In Linge G J R, Forbes D K, Ed. China's Spatial Economy Recent Development and Reforms, pp. 129-43. Oxford University Press, Hong Kong, 1990.

[2] Yan H. Population distribution and internal migration in China since the 1950s. In Wang J, Hall T H, Ed. Population and Development Planning in China, pp.212-34. Allen \& Unwin: North Sydney, 1991.

[3] Shen J. Rural development and rural to urban migration in China 1978-1990. Geoforum 1995; 26: 395-409.

[4] Shen J. Understanding dual-track urbanisation in post-reform China: conceptual framework and empirical analysis. Population, Space and Place 2006; 12(6): 497-516.

[5] Shen J. Estimating urbanization levels in Chinese provinces in 1982-2000. Int Stat Rev 2006; 74(1): 89-107.

[6] Smil V. China's Environmental Crisis: an Inquiry into the Limits of National Development. M E Sharpe Inc.: New York, 1993.

[7] $\mathrm{Hu}$ X, Mao H, Lu D. Problems and countermeasures of the sustainable socio-economic development in China's coastal region, ACTA Geogr Sin 1995; 10: 1-12.

[8] Shen J. China's future population and development challenges. Geogr J 1998; 164(1): 32-40.

[9] Shen J. Population growth, ecological degradation and construction in the western region of China. J Contemp China 2004; 13(41): 637-61.

[10] Gugler J, Ed. The Urbanization of the Third World. Oxford University Press: Oxford, 1988.

[11] Gilbert A. Third world cities: poverty, employment, gender roles and the environment during a time of restructuring. Urban Stud 1994; 31(4/5): 605-33.

[12] Chiu R L H. China's housing reform: the experiments in Shenzhen special economic zone. Asian Geogr 1993; 12: 47-56.

[13] Zhu J. Local growth coalition: the context and implications of China's gradualist urban land reforms. Int J Urban Reg Res 1999; 25: 534-48. 
[14] Shenzhen. Statistics Bureau. Shenzhen Statistical Year book 2007. China Statistics Press: Beijing, 2007.

[15] Wong K Y, Shen J, Ed. Resource Management, Urbanization and Governance in Hong Kong and the Zhujiang Delta. Chinese University Press: Hong Kong, 2002.

[16] Yeung Y M, Shen J, Ed. The Pan-Pearl River Delta: An Emerging Regional Economy in a Globalizing China. Chinese University Press: Hong Kong, 2008.

[17] Shen J. Inter-city relations between Hong Kong and Shenzhen: Implications for urban planning and governance. Plan Dev 2008; 23(2): 2-14.

[18] Chu KY D, Lee Fong M K, Lam K C, Ng Y T, Too S L and Wong $\mathrm{K}$ Y. Background to the recent development of Shenzhen municipality. Occasional Paper 12, Dept. of Geography and Geographical Research Centre, Chinese University of Hong Kong: Hong Kong, 1981.

[19] Lee Fong M K, Chu KY D, Lam K C, Ng Y T, Too S L, Wong K $\mathrm{Y}$. Implications of the recent development of Shenzhen municipality. Occasional Paper 14, Dept. of Geography and Geographical Research Centre, Chinese University of Hong Kong: Hong Kong, 1981.

[20] Wong K Y, Cai R Q, Chen H X, Shenzhen: Special experience in development and innovation. In Yeung Y M, Hu X, Ed. China's Coastal Cities: Catalysts for Modernization, pp. 264-90. University of Hawaii Press: Honolulu, 1992.

[21] Sun H. Planning of Shenzhen in the Pearl River Delta context. In Yeh A G O, Ed. Planning Hong Kong for the 21st Century, pp. 6176. Centre of Urban Planning and Environmental Management, University of Hong Kong: Hong Kong, 1996.

[22] Ng M K. Shenzhen: city profile. Cities 2003; 20(6): 429-41.

[23] Hsu S I. Environmental problems of the development of the Shenzhen special economic zone. Asian Geogr 1983; 2: 23-33

[24] $\mathrm{Ng} \mathrm{M} \mathrm{K}$. Sustainable urban development Issues in Chinese transitional cities: Hong Kong and Shenzhen. Int Plan Stud 2002; 7(1): 7-36.

[25] Lai X, Yang X. The impact of population growth on the ecological environment in the city of Shenzhen 1994: Proceeding of the 1994 Annual Conference of the Geographical Association of Guangdong. Guangzhou, China.

[26] Yang C. An emerging cross-boundary metropolis in China: Hong Kong and Shenzhen under 'two systems'. Int Dev Plan Rev 2005; 27(2): 195-225.

[27] Liu X, Heilig G K, Chen J, Heino M. Interactions between economic growth and environmental quality in Shenzhen, China's first special economic zone, Ecol Econ 2007; 62(3-4): 559-70.

[28] Ma H, Fang W, Ed. Economic Development in China: Present and Future. Economic Management Press: Beijing, 1993.

[29] Ng Tat-ming S. Law and development : the case of municipal land management regulations in Shenzhen Special Economic Zone. M.Phil Thesis. Chinese University of Hong Kong, Hong Kong, 1994.

[30] Lu T. The Pearl river delta: economic wonder of the 80's and the reinforced vantage of the 90's. In Zhujiang Delta Economic Development and Management Research Center, Zhongshan University, Ed. New Perspectives of the Economic Development of the Pearl River Delta, pp. 3-19. Zhongshan University Press: Guangzhou, 1995.
[31] Hu C T. The special economic zones and the development of the Zhujiang delta area. Asian Geogr 1989; 8: 71-87.

[32] Shen J, Wong K Y, Chu K Y. Regional economic growth and factor contributions in the Zhujiang delta region of south China. Asian Geogr 2001; 20(1\&2): 125-51

[33] Martin M F. Defining China's rural population. China Q 1992; No. 130: 392-401.

[34] Shenzhen Statistics Bureau. Shenzhen Statistical Yearbook 2006. China Statistics Press: Beijing, 2006.

[35] Chiu R L H. Housing affordability in Shenzhen special economic zone: A forerunner of China's housing reform. Housing Stud 1996; 11( 4): 561-80.

[36] Shenzhen Statistics and Information Bureau. Shenzhen Statistical Yearbook 1996. China Statistics Press: Beijing, 1996.

[37] Shenzhen Statistics and Information Bureau. Shenzhen Statistical Yearbook 2001. China Statistics Press: Beijing, 2001.

[38] Population Census Office and DPSSTS (Department of Population, Social, Science and Technology Statistics of NBS). Tabulation on the 2000 Population Census of the Peoples Republic of China (1) China Statistics Press: Beijing, 2002.

[39] Population Census Office of Guangdong Province. Tabulation on the 2000 Population Census of Guangdong Province (2). China Statistics Press: Beijing, 2002.

[40] Population Census Office of Guangdong Province. Tabulation on the 2000 Population Census of Guangdong Province (1). China Statistics Press: Beijing, 2002.

[41] Shen J. A study of the temporary population in Chinese cities. Habitat Int 2002; 26: 363-77.

[42] Zhu Y. China's floating population and their settlement intention in the cities: Beyond the Hukou reform. Habitat Int 2007; 31(1): 6576.

[43] Brown L. Who Will Feed China? Wake-up Call for a Small Planet. Earthscan Publications Ltd.: London, 1995.

[44] Shen J. Modelling national or regional grain supply and food balance in China. Environ Plan A 2000; 32: 539-57.

[45] Guangzhou Municipal Statistics Bureau. Guangzhou Statistical Yearbook 2006. China Statistics Press: Beijing, 2006.

[46] Shenzhen city government. $11^{\text {th }}$ five-year overall plan for economic and social development of Shenzhen city. Shenzhen city government: Shenzhen, 2006.

[47] Department of Urban Socio-economic Survey, NBS (National Bureau of Statistics) 2005 China City Statistical Yearbook. China Statistics Press: Beijing, 2005.

[48] National Bureau of Statistics. China Statistical Yearbook 2006 China Statistical Press: Beijing, 2006.

[49] Guangdong Provincial Bureau of Statistics. Guangdong Statistical Yearbook 1992. China Statistics Press: Beijing, 1992.

[50] Guangdong Provincial Bureau of Statistics. Guangdong Statistical Yearbook 1996. China Statistics Press: Beijing, 1996.

[51] Guangdong Provincial Bureau of Statistics. Guangdong Statistical Yearbook 2001. China Statistics Press: Beijing, 2001.

[52] Guangdong Provincial Bureau of Statistics. Guangdong Statistical Yearbook 2006. China Statistics Press: Beijing, 2006.

[53] Guangdong Provincial Bureau of Statistics. Guangdong Statistical Yearbook 2007. China Statistics Press: Beijing, 2007.

[54] Shen J, Feng Z, Wong KY. Dual-track urbanization in a transitional economy: the case of Pearl River Delta in south China. Habitat Int 2006; 30: 690-705. 